\title{
El cuerpo, más allá del falo, la imagen y la castración
}

\section{The body: beyond the image, the phallus and the castration}

\section{Sergio Zabalza}

\section{RESUMEN}

La equiparación de las tres dimensiones de la palabra: real, simbólico e imaginario, le permiten a Lacan conformar una noción de cuerpo apta para proponer el equívoco significante como modo privilegiado de la interpretación analítica. El hilo de la alteridad posibilita advertir que el sentido -en tanto partenaire del significantecede su lugar en sus últimos seminarios a la sustancia gozante, ese misterio que -en tanto real- articula las palabras con el cuerpo. De esta manera, conforme el falo cede su lugar como referente último de la significación, el síntoma se reduce a una escritura que no comunica nada. Aquí la nominación no describe , tan solo acompaña la nada que la disyunción entre los tres registros dibujan en el nudo borromeo. No en vano, Lacan observa que el cuerpo es un agujero del cual no tenemos idea, con toda la carga metafísica que tal palabra comporta en tanto representación disponible a la visión del pensamiento, residuo imaginario de la perspectiva aristotélica que otorgaba aliento a la castración imaginaria. El cuerpo que Lacan propone

\section{ABstract}

The equation of the three dimensions of the word: real, symbolic and imaginary, allows Lacan to conform a notion of body apt to propose the significant misunderstanding as a privileged mode of analytic interpretation. The thread of alterity makes it possible to see that meaning -as a partenaire of the signifieryields its place in its last seminars to the jouissance substance, that mystery which -as real- articulates words with the body. In this way, as the phallus relinquishes its place as the ultimate referent of signification, the symptom is reduced to a writing that communicates nothing. Here the nomination does not describe, only accompanies the nothing that the disjunction between the three registers draw in the Borromean knot. Not in vain, Lacan observes that the body is a hole of which we have no idea, with all the metaphysical load that such word implies as available representation to the vision of thought, imaginary residue of the Aristotelian perspective that gave breath to the imaginary castration. The body that 
responde a un imaginario no especular, producto de un decir que el campo femenino (la prójima) actualiza más allá de todo universal.

Palabras Claves:

Cuerpo - Imaginario - Falo - Goce Síntoma
Lacan proposes responds to a non-specular imaginary, product of a saying that the feminine field (the female neighbor) updates beyond all universal.

\section{KEYWORDS:}

Body - Imaginary - Phallus - Jouissance Sympton 
Los vertiginosos cambios suscitados en el sentido común que ampara la relación entre los sexos; las posibilidades abiertas por la ciencia que hacen obsoleto el refrán según el cual Madre hay una sola; junto con el advenimiento legal de posiciones sexuadas disidentes respecto del tradicional binarismo entre hombre y mujer, hacen pertinente el abordaje del cuerpo bajo el sesgo que brinda la alteridad del semejante en el contexto de un empuje a satisfacciones de corte autoerótico y adictivo, hoy alentadas por el régimen neoliberal que impera en el planeta. Un mandato por el cual las personas quedan capturadas en el hedonismo y el culto a la estética, con la misma rigurosidad que la biopolítica hace del orden genético un arma para la segregación.

Por rara paradoja, este individualismo distintivo de nuestra época corre parejo con el empobrecimiento de la relación del sujeto con su propio cuerpo, un síntoma generalizado resultante de la ausencia de las palabras necesarias para tramitar la angustia, y de la cual los laboratorios hoy hacen su agosto al sumergir en la clandestinidad del fármaco los motivos del padecer subjetivo. Se hace evidente entonces el estatuto del cuerpo en tanto Otro. De allí quizás la relevancia que hoy cobran los discursos imperantes a la hora de tomar decisiones que competen al cuerpo, por ejemplo: el tema de la interrupción voluntaria del embarazo que las mujeres han impuesto en la polis para terminar con la clandestinidad o las operaciones que los sujetos se practican para cambiar de sexo. Entonces, para decirlo todo: no hay cuerpo sin prójimo. Aquí es donde el punto de vista lacaniano -según el cual el ser hablante tiene un cuerpo en lugar de ser un cuerpo-, hace toda la diferencia respecto a las concepciones identitarias, cuyas buenas inten- ciones (que suelen ser las peores) echan por la puerta viejos mandatos para luego dejarlos entrar por la ventana con sesgos más sádicos y exigentes que los anteriores.

En esta perspectiva poco tienen que hacer los prejuicios psicopatológicos que pretenden encerrar en casilleros diagnósticos lo que en muchos casos constituyen anudamientos subjetivos merecedores de toda la dignidad. No en vano dice Lacan: "Lo que el hombre sabe hacer, con su imagen (...) permite imaginar la forma en que se las arregla con el síntoma" (Lacan, 1976/1977, p. 10) En otros términos, uno se las arregla con el partenaire síntoma (eso que no aparece en el espejo) manipulando su propia imagen. El encuentro con el signo que muerde la carne -el goce- constituye desde esta perspectiva el punto donde la diferencia que encarna el semejante provee un nombre a lo real en el siglo XXI. Se trata de que si -tal como observa Lacan-: "Cuando digo que No Hay Relación Sexual propongo muy precisamente esta verdad de que el sexo no define ninguna relación en el ser hablante" (Lacan, 2012, p. 13) , se goza más allá de los estereotipos que el género anatómico o el sexo eventualmente adoptado sugieran. El goce siempre es diverso respecto a la ilusión de completud, abyecto: prójima. De lo que hace con esta alteridad que desafía toda imagen y narcisismo depende que el encuentro de los cuerpos se oriente por una vía amorosa o por la reducción del semejante a la mera condición de objeto.

\section{PRÓJIMA: UN AMOR MÁS ALLÁ DEL NARCISISMO}

Aquí se hace por demás oportuno destacar la particular connotación que el término 
prójima guarda en tanto puta -mujer de dudosa conducta, dice el diccionario-, es decir ese objeto inquietante aunque atractivo capaz de amenazar el narcisismo del espejo provisto por la imagen estereotipada del semejante. No en vano, dice Lacan que: "es bien notable y comprensible que Dios nos aconseje no amar más que a nuestro prójimo y de ninguna manera limitarnos a nuestra prójima, ya que si nos dirigiéramos a nuestra prójima iríamos simplemente al fracaso" (Lacan, 2015, p. 30). Dicho sea de paso, la traducción en francés de prójimo en tanto próximo no podría sernos más propicia. Es que esta prójima es lo que de nosotres -hombres, mujeres y otros sexosse vuelve más clandestino, sintomático e intolerable. Desde esta perspectiva el campo femenino está en lo Otro del cuerpo, eso de lo cual -como dice Lacan- no se tiene idea: el acontecimiento de goce "antes de que se pueda establecer el sentido del encuentro" (Laurent, 2016, p. 58). De allí que plusvalor resultante de este exceso renuente a toda domesticación o educación constituye el punto de apoyo de una posición política que interroga la distribución y economía de goce entre los cuerpos de una comunidad hablante. Se insinúa una versión del amor más allá del narcisismo de la imagen. Aquí brindamos algunos trazos del abordaje del cuerpo a partir del lugar que Lacan, desde sus más tempranas formulaciones, otorga a la alteridad

\section{HACIA UN IMAGINARIO NO ESPECULAR}

Si damos por cierto que es sólo "como enteramente imaginario que el cuerpo subsiste”, (Lacan, 1975, p.12) hablar del cuerpo y con el cuerpo en Lacan supone un recorrido por el lugar que la alteridad ocupa en el eje Imaginario a lo largo de su enseñanza. De esta manera, el temprano privilegio otorgado a la imagen del otro en el célebre estadio del espejo (Lacan, 1988, p. 86) se transforma años después -tal como más arriba mencionamos- en un "saber hacer con" lo que de la imagen no entra en el dominio especular y sin embargo conforma la experiencia del trauma que lalengua impone en el cuerpo: el síntoma de uno, es decir el cuerpo que uno tiene, a condición de ignorarlo tras la ilusión del cuerpo donde "eso se siente" (Lacan, 2012b, p. 596).

No es ajeno el trayecto del registro Simbólico a esta basculación que -por asimilar la imagen del cuerpo al síntoma- inclina el énfasis de su enseñanza sobre lo Real en tanto radical cuestionamiento a la referencia que presta el sentido. Desde aquel Gran Otro que sancionaba el júbilo del niño ante el reflejo del cristal hasta el decir del Nombre propio que cierne la singularidad, un trayecto que transita la comunicación para recalar en la escritura; franquea el síntoma histérico para llegar a lo que hace "acontecimiento de cuerpo" (Lacan, 2012b, p. 595); propone al síntoma como suplencia del referente; se sirve del sentido para ocuparse del goce; desconfía de la identificación con el inconsciente a favor de creer en un Real sin comulgar con él; hace de la disyunción que funda el nudo entre las tres dimensiones de la palabra ( Real, Simbólico e Imaginario) un operador preferible al falo y la castración; y privilegia el equívoco a toda otra forma de interpretación, permite hacer del trauma la letra de una nominación que no convoca otro referente más que el cuerpo gozando en su singularidad, todo lo cual resulta en una alteración inédita en la manera de hablar: ese mentado "saber hacer con" cuya pragmática traduce " de qué modo el síntoma del Uno 
solo del todo, que no habla, se articula con el Otro.

\section{LOM: NADA DE VISTA}

A propósito de este imaginario que no responde a la dimensión especular, en su conferencia “Joyce El Síntoma" Lacan examina el primer tener del cuerpo. Dice: "Lo importante es desde qué punto -se suele decir 'de vista' ¿lo discutimos?- lo que importa pues sin precisar desde dónde, es darse cuenta que $\{d e\}^{1} \mathrm{LOM}^{2}$ tiene un cuerpo -y que la expresión sigue siendo correcta" (Lacan, 2012b, p. 592). Correcta porque el partitivo (de) que antecede a LOM explica que no hay un yo. Según Eric Laurent: "Es una atribución que precede a todo haber y que es definida como anterior al estadío del espejo, antes de la relación del sujeto con la vista“(Laurent, 2016, p. 108). Lo interesante es que la expresión punto de vista aquí es cuestionada a partir de que en francés la palabra punto (point) significa punto pero también nada. Es decir, Lacan propone considerar un nada de vista. El cuerpo se produce por el impacto de un decir y no por las identificaciones imaginarias que pretenden encerrar el goce singular en la estereotipias del sexo anatómico. Por algo, el agujero constitutivo del cuerpo coincide con esta nada donde habita el ser hablante [parlêtre], olvidado tras la ilusión con que el sujeto goza al decir "mi cuerpo".

Desde esta perspectiva, tanto parlêtre como LOM son nombres de los que Lacan se sirve para abordar ese imaginario constitutivo del cuerpo que, por no ingresar en el campo especular, no resulta afín al sujeto en tanto lo que un significante representa para otro significante. Esta nominación -en tanto Nombre propio- cuenta como referente tan solo con un cuerpo gozando en su singularidad. Al respecto, dice Lacan: "Lo propio del sentido es que en él se nombra algo y no que uno se hace comprender" [Lacan, 1975b]

\section{HaCIA LOS ANTECEDENTES FREUDIA- NOS: EL CUERPO Y EL INCONSCIENTE}

En otros términos, la alteridad que le corresponde al Nombre propio es la disyunción entre los tres registros (Imaginario Real y Simbólico) que abarcan la dimensión de la palabra, un partenaire que por asimilarse a la nada explica tanto la ilusión en que el sujeto funda su narcisismo como la preeminencia que, respecto a la imagen, Lacan otorga al cuerpo en tanto trauma resultante del impacto de un decir, un agujero que remite a lo "no reconocido" del ombligo del sueño freudiano. Al respecto, dice: "La antigua noción del inconsciente, lo Unerkannt, se apoyaba precisamente en nuestra ignorancia de lo que pasa en nuestro cuerpo" (Lacan, 2006a, p. 147). Por algo, en su respuesta a Marcel Ritter de enero de 1975, identifica este Unerkannt con lo que Freud llama Urverdrängt, lo reprimido primordial u original, o si se quiere: " 'un nudo en lo decible' comparable con el agujero en la pulsión” (Lacan, 2006a, p. 233), tal como recuerda Jacques Alain Miller en su Nota paso a paso. No extraña entonces esta impactante definición con la cual Lacan pone negro sobre blanco cuando en su conferencia de Niza de 1974 dice: "el hombre [...] ama a su imagen como lo que le es más prójimo, es decir, su cuerpo. Simplemente, de su cuerpo no tiene estrictamente ninguna idea. 
Cree que es yo ( moi). Cada uno cree que es él. Es un agujero. Y después, afuera está la imagen. Y con esta imagen hace el mundo" (Lacan, 1974).

\section{El objeto a}

El paso para ese imaginario no especular que alberga una nada de vista es el objeto $a$, el pequeño otro que adquiere un estatuto real durante el seminario de $\mathrm{La} \mathrm{An-}$ gustia. En efecto, en su clase del 28 de noviembre de 1962 , vuelve a recurrir a la experiencia del ramillete invertido. $\mathrm{Al} \mathrm{co-}$ mentar la escena en que Hamlet "tiene a su enemigo a su alcance" (a saber: Claudio, rival imaginario si los hay), Lacan destaca que el príncipe:

sólo sabe articular lo que cualquier oyente puede percibir como una escapada. Se esconde tras un pretexto , a saber, que atrapó a su enemigo en un momento demasiado santo -el rey está rezando- como para decidirse, golpeándolo en ese instante, a hacerlo acceder directamente al cielo". [Lacan, (2006 b, p. 46].

Comentario tras el cual la mención de Ofelia y la figura del duelo aparecen como antesala del punto decisivo en que un objeto se desmarca del campo especular en su enseñanza. Dice:

Aquí podemos medir la distancia que hay entre dos clases de identificaciones imaginarias. Está la identificación con i (a) (...) y está la identificación más misteriosa, cuyo enigma comienza a desarrollarse aquí, con el objeto del deseo en tanto tal, a"[

Lacan, 2006 b, pp. 46 y 47]

Aparece de esta manera, en la figura de la suicidada Ofelia, el objeto de deseo por fuera del dominio especular constituyéndose como perdido. Y sabido es que sólo a partir de allí Hamlet accede al acto y mata a Claudio. Es aquí cuando retoma la experiencia del ramillete invertido que había presentado diez años atrás para decir: "No todo el investimiento libidinal pasa por la imagen especular. Hay un resto." [Lacan, 2006 b, p. 49]

Resto heredado del capítulo VII de $L a$ Interpretación de los sueños, el Unerkannt que identifica al Urverdrängt de lo reprimido primordial, ese 'nudo en lo decible' comparable con el agujero en la pulsión" [ Lacan, 2006 a, p. 233] , el grano de arena que -según Freud- las neurosis actuales aportan a las psiconeurosis y que años después-al intentar formalizar un cuerpo más allá de Freud y del amor al padre- Lacan ubica en una lógica que se sirve del sentido para ir más allá del sentido. Tenemos entonces que con el objeto a aparece ahora un resto cuya radical condición es constituirse como perdido y que -vía la angustiale disputa al sentido el lugar como principal referente del significante.

\section{JOYCE Y EL EQUÍVOCO SIGNIFICANTE}

Lacan está proponiendo un cuerpo incompatible con la posibilidad de que el psicoanálisis se reduzca a una "religión de la castración” (Laurent, 2016, p. 149 ). Dice:

Los hijos aman al padre en la medida en que están privados de mujer. Se 
trata de algo completamente singular y sorprendente que solo sanciona la intuición de Freud. Yo intento dar otro cuerpo a esta intuición. [Lacan, 2006, p. 148].

De allí que se sirva de Joyce para continuar su pesquisa en torno al campo inaccesible a la representación, ese cuerpo anterior a la creencia que escapa al dominio especular.

Desabonado del inconsciente, es decir, afectado de una pérdida primordial "que no pide más que irse, desprenderse como una cáscara" (Lacan, 2006, p. 147), el escritor irlandés emprende una suerte de epopeya literaria con la que eleva "El síntoma, en la medida que nada lo liga a lo que es lalengua misma (...), a la potencia del lenguaje sin que, sin embargo, nada de ello sea analizable"- (Lacan, 1975 c, p. 164). En otros términos, a falta de conexión con lalengua -esa "secreción del cuerpo" (Miller,2013, p. 71) a partir de la cual el neurótico accede a la adoración narcisista que le permite identificarse a su imagen-, Joyce hace de la escritura un artificio para anudarse el cuerpo, es decir: se arma un cuerpo sin la garantía del Nombre del Padre. A partir de aquí para cualquier ser hablante "el poder no está articulado con el falo y la copulación. Es poder hacer algo con lo imposible de escribir la relación sexual". (Laurent, 2016, p. 72])

\section{A MANERA DE CONCLUSIÓN}

Tal como más arriba manifestamos: si es cierto que solo existe un cuerpo como imaginario, hablar del cuerpo y con el cuerpo en Lacan supone un recorrido por el lugar que la alteridad ocupa en el eje Imaginario a lo largo de su enseñanza. Nuestra conjetura es que, conforme su clínica se orienta por lo Real en tanto radical cuestionamiento al sentido del que se alimenta el síntoma, Lacan propone un cuerpo hablante ausente del dominio especular, al que se accede por medio del equívoco significante con el fin de incidir en la singularidad de un goce no negativizable. Esto es: saber arreglárselas con la imagen al hacer del síntoma una nominación cuya única referencia es el trauma de lalengua, ese agujero a partir de cuyo borde, sin embargo, se constituye la ilusión del cuerpo donde "eso se siente". A partir de hacer lugar al goce que los cuerpos portan en su singularidad, esta perspectiva propone un radical cuestionamiento de las estereotipias con que el sentido común consagra los prejuicios en que se funda la segregación que, por ejemplo, hoy sostiene al régimen neoliberal.

\section{Notas Ampliatorias}

1 La edición española no incluye el partitivo de, sin el cual no es entiende la frase.

2 Aquí Lacan subvierte, no sin ironía, el sentido común que usa al género masculi- 
no para nombrar a la humanidad toda mediante el juego homofónico de la expresión LOM ( L’homme, en francés).

\section{REFERENCIAS BIBLIOGRÁFICA}

Lacan, J. (1976/1977) El Seminario: Libro 24, “ L'insu que sait de l'une bevue s'aile á mourre", lección del 16 de noviembre de 1976, parcialmente establecida por J. A Miller para su publicación en $\mathrm{Or}$ nicar?, no 12/13, 1977, pp. 4-9. Inédito, (tomado de un texto sin indicación editorial, trad. Susana Sherar y Ricardo Rodríguez Ponte, p. 10)

( 2012 a) El Seminario: Libro 19, “ ...ou pire”, Buenos Aires, Paidós, 2012.

$$
\text { ( } 2015 \text { a) "La Tercera" Lacan, J. }
$$
: “La tercera" en Revista Lacaniana, EOL, No 18 , mayo 2015, pp. 9-32.

(1975) "Respuesta a una pregunta de Marcel Ritter”. Inédito. Tomado de El cuerpo en la orientación lacaniana. Selección de textos de la Comisión de Publicaciones de la NEL-Medellin, para uso restringido por los usuarios de la biblioteca de la sede.

(1988) “ El estadio del espejo como formador de la función del yo (je) tal como se nos revela en la experiencia analítica", en Escritos 1, Buenos Aires, Siglo XXI, 1988. ( 2012 b) conferencia "Joyce El Síntoma”, en Otros Escritos, Buenos Aires, Paidós, 2012, pp. 591-597. ( 1975 b) El Seminario: Libro XXII, "RSI", lección del 11 de marzo de 1975. Inédito. Traducción de la versión de M. Chollet y notas de traducción de
Rodriguez Ponte, sin referencia editorial, p. 97.

( 1974) "El fenómeno lacaniano", Conferencia pronunciada en el Centro Universitario Mediterráneo (CUM) de Niza, el 30 de noviembre de 1974. Texto establecido por Jacques Alain Miller a partir de la transcripción realizada por Mme Elisabeth Geblesco desde una grabación de M. Francois Péissier. Traducido al castellano por Miquel Bassols. Publicado en la revista "Uno por Uno" $\mathrm{N}^{\circ} 46$

( 2006 b) El Seminario: Libro 10, "La Angustia”, Buenos Aires, Paidós, 2006. Lacan, J. (2006a) El Seminario: Libro 23, "El sinthome”, Buenos Aires, Paidós, 2006.

( 1975 c) “ Joyce El Síntoma”, en El Seminario: Libro 23, " El sinthome”, Buenos Aires, Paidòs, 2006, pp. 159-166.

LAURENT, E. ( 2016) “ El reverso de la biopolítica”, Buenos Aires, Paidós, 2016. Miller, J. A. ( 2013) "Piezas sueltas", Buenos Aires, Paidós, 2013.

\section{COMO CITAR ESTE ARTÍCUlO:}

Zabalza, S (2019). El cuerpo, mas allá del falo, la imagen y la castración en Revista Psicoanálisis en la Universidad $N^{\circ} 3$. Rosario, Argentina. UNR editora.

\section{Sergio Zabalza}

Licenciado en psicología (UBA); Magíster en Clínica Psicoanalítica UNSAM); y actual doctorando en la Universidad de Buenos Aires. Desarrolla su práctica psicoana- 
lítica en privado y colabora en el ámbito público como supervisor en hospitales públicos y equipos de docentes de Educación Especial. Ex integrante del Dispositivo de Hospital de Día y del Equipo de Trastornos Graves Infanto Juveniles del Hospital Alvarez, donde además fue docente de posgrado. Integra como Profesor Adjunto la Cátedra de Clínica Psicológica: Adolescencia en la Universidad de las Ciencias Empresariales y Sociales (UCES). Es autor de la Hospitalidad del Síntoma (Letra Viva, 2005); El Lugar del Padre en la Adolescencia (Letra Viva, 2010); Neoparentalidades. El Porvenir de la Diferencia ( Letra Viva, 2012); La Palabra que falta es Una mujer ( Letra Viva, 2013 -en coautoría con Carolina Rovere); Intimidados en Internet ( Letra Viva, 2014) y El Cuerpo impactado ( Letra Viva, 2018). Ha publicado más de trescientos artículos en los diarios Página12; Clarín y Perfil, como también numerosos artículos en la revista Imago Agenda y el sitio de psicoanálisis El Sigma ( www.elsigma) donde coordina la sección Lecturas. Coordina desde hace varios años seminarios virtuales en la Comunidad Russell. 